спортивного опыта, который, вероятно, окажет положительное влияние на пожизненную физическую активность и приверженность спорту.

$$
* * *
$$

1. Trudeau, F., \& Shepherd, R.J. (2005). Contribution of school programs to physical activity levels and attitudes in children and adults. Sports Medicine (Auckland, N.Z.), 25, 89-105.

2. Allison, K.R., Dwyer, J.J.M., \& Makin, S. (1999). Perceived barriers to physical activity among high school students. Preventive Medicine, 28, 608-614.

3. Thompson, A.M., Humbert, M.L., \& Mirwald, R.L. (2003). A longitudinal study of the impact of childhood and adolescent physical activity experiences on adult physical activity perceptions and behaviors. Qualitative Health Research, 13, 358-377.

4. Fairclough, S., Stratton, G., \& Baldwin, G. (2002). The contribution of secondary school PE to lifetime physical activity. European Physical Education Review, 8, 69-86.

5. U.S. Department of Health and Human Services. (1997). Center for Disease Control: Guidelines for school and community programs to promote lifelong physical activity among young people. 2006

6. Stein, E.L. (1983). Starting intramural programs in elementary/secondary schools. JOPERD, 54, 19.

7. Ewing, M.E., Seefeldt, V., \& Brown, T.P. (1996). Role of organized sport in the education and health of American children and youth. E

8. Seefeldt, V., Ewing, M., \& Walk, S. (1992). Overview of youth sports programs in the United States. Washington, DC: Carnegie Council on Adolescent Develo

9. Perkins, D.F., Jacobs, J.E., Barber, B.L., \& Eccles, J.S. (2004). Childhood and adolescent sports participation as predictors of participation in sports and physical fitness activities during young adulthood. Youth \& Society, 35, 495-520.

\title{
Маликов А.O. \\ Воздействие монетарной политики на фондовые рынки развитых стран
}

Финансовый университет при Правительстве Российской Федераичии (Россия, Москва)

doi: $10.18411 / s r-10-04-2021-50$

\section{Аннотация}

Данная статья посвящена исследованию воздействия монетарной политики на развитие фондового рынка развитых стран, в рамках данной статьи мы рассматривали развитие фондовых рынков стран Евросоюза. Выбирая факторы, которые могут повлиять на развитие рынка ценных бумаг, мы учитывали особенности современной монетарной политики, направленной на контроль экономик развитых стран от условий на стратегических товарных рынках и темпов инфляции, доллара и евро.

Моделирование процесса развития фондового рынка в странах Евросоюза может осуществляться на основе применения экономико-математических методов. В частности, мы провели корреляционно-регрессионный анализ зависимости прибыльности фондового рынка стран Евросоюза от ряда макроэкономических факторов.

Одним из теоретических обоснований влияния монетарной политики на доходность акций может быть механизм кредитного канала, разделенный на канал баланса и канал банковского кредита. Во-первых, негативный шок монетарной политики увеличивает затраты по внешним займам и снижает стоимость активов фирмы, которые могут служить залогом новых кредитов. Это уменьшает доступ к кредитам и, в целом, к любому типу внешних заимствований, что приводит к тому, что фирмы вынуждены снижать уровень инвестиций. Тогда конечными последствиями шока может быть снижение денежных потоков и норм прибыли. Для банковского кредитного канала характерна несколько другая ситуация: ограничительный заем заставляет банки сокращать предложение кредитов и повышать ставки. Это также оказывает негативное влияние на денежный поток фирм, доходность акций.

Ключевые слова: монетарная политика, фондовый рынок, развитые страны, экономико-математическое моделирование, корреляция, регрессия, доходность, акции. 


\section{Abstact}

This article is devoted to the study of the impact of monetary policy on the development of the stock market in developed countries; within the framework of this article, we examined the development of the stock markets of the EU countries. Choosing the factors that can affect the development of the securities market, we took into account the peculiarities of modern monetary policy aimed at controlling the economies of developed countries from conditions in strategic commodity markets and inflation rates, dollar and euro.

Modeling the development process of the stock market in the EU countries can be carried out on the basis of the use of economic and mathematical methods. In particular, we carried out a correlation-regression analysis of the dependence of the profitability of the stock market in the EU countries on a number of macroeconomic factors.

One of the theoretical justifications for the influence of monetary policy on stock returns may be the credit channel mechanism, divided into the balance channel and the bank credit channel. First, a negative shock to monetary policy increases borrowing costs and lowers the value of a firm's assets, which can serve as collateral for new loans. This reduces access to credit and, in general, to any type of external borrowing, which leads to the fact that firms are forced to reduce the level of investment. Then the ultimate consequences of the shock can be a decrease in cash flows and profit margins. A somewhat different situation is characteristic of the bank credit channel: restrictive loans force banks to reduce the supply of loans and raise rates. It also has a negative impact on firms' cash flow, stock returns.

Keywords: monetary policy, stock market, developed countries, economic and mathematical modeling, correlation, regression, profitability, stocks.

Актуальность темы статьи обозначается тем, что основная сложность измерения влияния денежно-кредитной политики связана с проблемой эндогенности, поскольку участники фондового рынка устанавливают ожидания относительно действий кредитных и денежных органов. В связи с этим следует изолировать шоки неожиданные направления в политике, наибольший интерес к реакции рынка.

Цель исследования состоит в доказательстве перспективности экономикоматематического моделирования как инструмента выявления зависимости развития фондового рынка от факторных показателей, проводимых в развитых странах монетарной политики.

Задачи исследования сводятся к выявлению тенденций развития фондовых рынков развитых стран.

Результаты исследования. Нами построена экономико-математическая модель, выявляющая факторы, влияющие на развитие фондовых рынков развитых стран. Исходные данные представлены в таблице 1 [6].

Таблий 1

Исходные данные для проведения корреляччионно-регрессионного анализа [6]

\begin{tabular}{|c|c|c|c|c|c|}
\hline Год & $\begin{array}{c}\text { Совокупные } \\
\text { активы рынка } \\
\text { ценных бумаг } \\
\text { Еврозоны, млрд. } \\
\text { евро }\end{array}$ & $\begin{array}{c}\text { Агрегат М3, } \\
\text { млрд. евро }\end{array}$ & $\begin{array}{c}\text { Общий объем } \\
\text { выданных } \\
\text { кредитов в } \\
\text { Еврозоне, млрд. } \\
\text { евро }\end{array}$ & $\begin{array}{c}\text { Объем } \\
\text { привлеченных } \\
\text { средств } \\
\text { банковским } \\
\text { сектором } \\
\text { Еврозоны, млрд. } \\
\text { руб. }\end{array}$ & $\begin{array}{c}\text { Курс обмена } \\
\text { долл. США к } \\
\text { евро }\end{array}$ \\
\hline 2017 & 2283,2 & 9830,0 & 4073,0 & 2004,3 & 1,3281 \\
\hline 2018 & 1977,6 & 10305,8 & 3892,3 & 1692,9 & 2,3285 \\
\hline 2019 & 1994,0 & 10403,6 & 3993,3 & 1685,2 & 1,1621 \\
\hline 2020 & 1960,7 & 10440,2 & 3969,3 & 1683,1 & 1,1350 \\
\hline
\end{tabular}


Таким образом, в качестве зависимой переменной $(\mathrm{У})$ определен общий объем активов рынка ценных бумаг Евросоюза, а в качестве независимых переменных [1]:

- агрегат М3 - X1;

- общий объем выданных кредитов в Еврозоне - X2;

- объем привлеченных средств банковским сектором Евросоюза - X3;

- обменный курс евро и долл. США - Х4.

Проведем корреляционный анализ для отбора факторов, которые в наибольшей степени оказывают влияние на зависимую переменную в таблице 2 [13].

Таблица 2

Коэффичиенты парной коррелящуии [6]

\begin{tabular}{|l|c|c|c|c|c|}
\hline \multicolumn{1}{|c|}{ Признаки } & $\begin{array}{c}\text { Совокупные } \\
\text { активы } \\
\text { рынка } \\
\text { ценных } \\
\text { бумаг } \\
\text { Еврозоны, } \\
\text { млрд. евро }\end{array}$ & $\begin{array}{c}\text { Агрегат } \\
\text { евро млрд. }\end{array}$ & $\begin{array}{c}\text { Общий объем } \\
\text { выданных } \\
\text { кредитов в } \\
\text { Еврозоне, млрд. } \\
\text { евро }\end{array}$ & $\begin{array}{c}\text { Объем } \\
\text { привлеченных } \\
\text { средств } \\
\text { банковским } \\
\text { сектором } \\
\text { Еврозоны, млрд. } \\
\text { руб. }\end{array}$ & $\begin{array}{c}\text { Курс } \\
\text { обмена } \\
\text { долл. } \\
\text { США к } \\
\text { евро }\end{array}$ \\
\hline $\begin{array}{l}\text { Совокупные активы } \\
\text { рынка ценных бумаг } \\
\text { Еврозоны, млрд. } \\
\text { Евро }\end{array}$ & 1 & 1 & & & \\
\hline $\begin{array}{l}\text { Агрегат М3, млрд. } \\
\text { евро }\end{array}$ & $-0,98059$ & $-0,69646$ & 1 & & \\
\hline $\begin{array}{l}\text { Общий объем } \\
\text { выданных кредитов в } \\
\text { Еврозоне, млрд. евро }\end{array}$ & 0,823414 & & & \\
\hline $\begin{array}{l}\text { Объем привлеченных } \\
\text { средств банковским } \\
\text { сектором Еврозоны, } \\
\text { млрд. руб. }\end{array}$ & 0,996217 & $-0,98459$ & 0,80116 & & \\
\hline $\begin{array}{l}\text { Курс обмена долл. } \\
\text { США к евро }\end{array}$ & $-0,18544$ & $-0,00653$ & $-0,70477$ & $-0,16297$ & 1 \\
\hline
\end{tabular}

Полученные данные в таблице 2 свидетельствуют о том, что на совокупные активы рынка ценных бумаг Еврозоны наиболее сильно влияют все показатели, кроме обменного курса евро по отношению к доллару США. Следовательно, данные показатель не будет приниматься нами для построения регрессионной модели [8].

Регрессионный анализ проведем в программе Microsoft Excel. B результате нами получены следующие коэффициенты линейной функции зависимости (таблица 3) [10].

Таблица 3

Коэффициентьы линейной функциии зависимости [6]

\begin{tabular}{|l|c|}
\hline \multicolumn{1}{|c|}{ Признак } & Коэффициенты \\
\hline Ү-пересечение & 4930,155 \\
\hline Агрегат МЗ, млрд. евро & $-0,50148$ \\
\hline Общий объем выданных кредитов в Еврозоне, млрд. евро & 0,636223 \\
\hline Объем привлеченных средств банковским сектором Еврозоны, млрд. руб. & $-0,15404$ \\
\hline
\end{tabular}

Следовательно, полученное уравнение имеет следующий вид:

$\mathrm{y}=4930,155-0,50148$ X1 + 0,636223 X2 - 0,15404 X3

Видно, что каждый из факторов оказывает на зависимую переменную с разной степенью влияния и в различном направлении. Например, коэффициент агрегата М3 имеет отрицательное значение, то есть его влияние является обратным. При этом из всех факторов он оказывает наибольшее воздействие на совокупные активы рынка ценных бумаг Еврозоны. 
На рисунке 1 представлен график зависимости этих показателей.

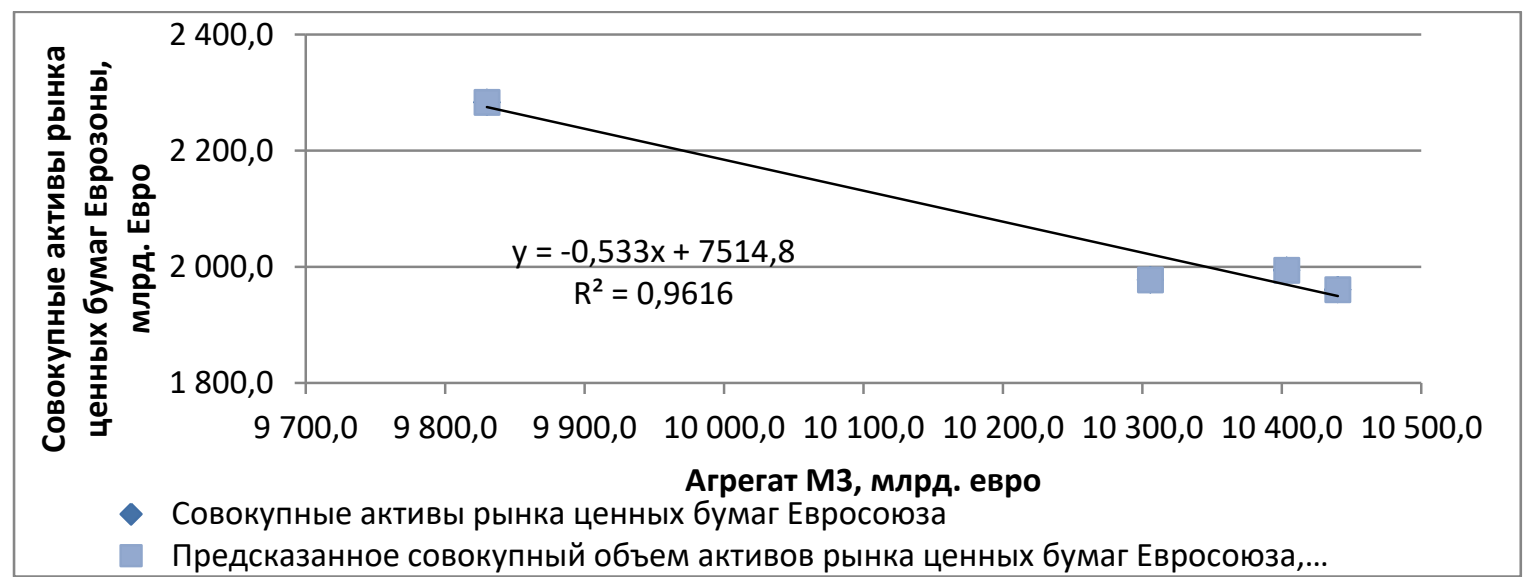

Рис. 1. График функции зависимости совокупных активов рынка ценных бумаг Евросоюза от величинь агрегата МЗ в странах Евросоюза

С помощью математического моделирования можно осуществить прогноз показателей развития фондового рынка в странах Евросоюза. Проведем расчет прогнозных знчений для объемов выдаваемых кредитных средств с помошью трендового анализа [5].

На рисунке 2 представлен график совокупных актиовов рынка ценных бумаг Евросоюза во времени.

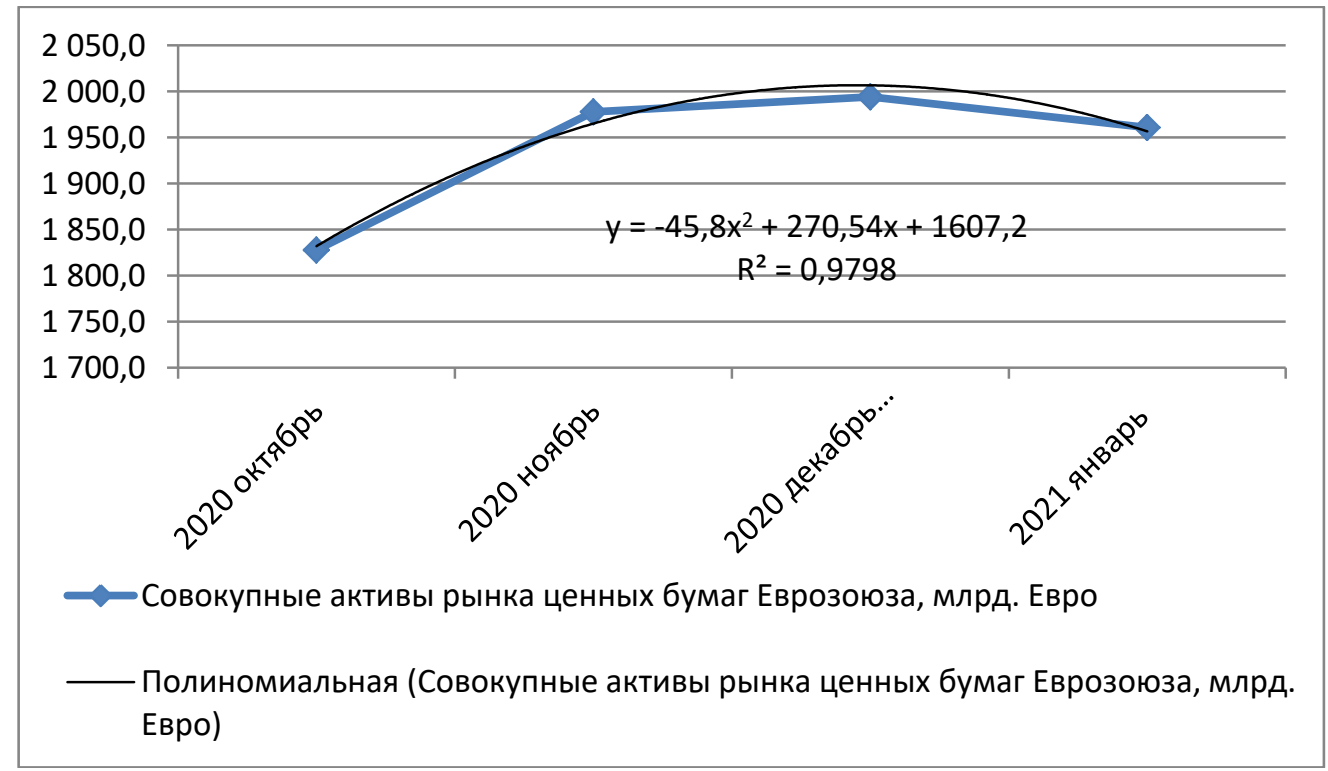

Рис.2. График совокупных актиовов рынка иченных бумаг Евросоюза во времени

Далее на основании полученной функции рассчитаем прогнозные значения помесячно до мая 2021 года в таблице 4.

Таблица 4

Прогноз совокупных актиовов рынка ченныхх бумаг Евросоюза, млрд. евро [6]

\begin{tabular}{|c|r|}
\hline Год & Общий объем выданных кредитов в Еврозоне, млрд. евро \\
\hline 2014 ноябрь & 1827,7 \\
\hline 2014 декабрь & 1977,6 \\
\hline 2015 январь & 1994,0 \\
\hline 2015 февраль & 1960,7 \\
\hline 2015 март & 1814,5 \\
\hline
\end{tabular}




\begin{tabular}{|c|r|}
\hline 2015 апрель & 1581,2 \\
\hline 2015 май & 1256,3 \\
\hline 2015 июнь & 839,8 \\
\hline
\end{tabular}

Полученные данные свидетельствуют о том, что при прочих равных условиях ежемесячные совокупные актиовы рынка ценных бумаг Евросоюза будет сокращаться.

Полученная регрессионная модель позволяет прогнозировать изменение совокупных активов рынка ценных бумаг развитых стран при изменении соответствующих показателей. При этом выяснилось, что основное влияние на величину совокупных активов рынка ценных бумаг развитых стран оказывают показатели агрегата М3 и общий объем выданных кредитов [11].

\section{Выводы}

С дальнейшим замедлением мировой экономики еврозону ждет довольно сложная версия дефляционного кризиса.

В 2021 году политика ЕЦБ, безусловно, будет оставаться стимулирующей (на текущем уровне), а европейские фондовые индексы будут продолжать падать или, в лучшем случае, стагнировать, потому что экономика падает, а ужесточение глобальной денежно-кредитной политики только укрепится [12].

В целях совершенствования деятельности фондовых рынков развитых стран по прогнозированию совокупных активов фондового рынка как основного финансового показателя устойчивости фондового рынка предлагается использовать средства регрессионного анализа для измерения их доходности.

$$
* * *
$$

1. Белоглазова Г.Н. Деньги. Кредит. Банки: учебник / Под ред. Г.Н. Белоглазовой. - М.: Высшее образование, 2019. - $392 \mathrm{c.}$

2. Братко А. Г. Центральный банк в банковской системе России / А.Г. Братко. - М.: Спарк, 2017. $335 \mathrm{c}$.

3. Кабир Л.С. Преимущества и угрозы режима плавящего валютного курса / Л.С. Кабир, И.А. Яковлев, С.П. Савинский, С.И. Никулина, И.Д. Раков. // Национальные интересы: приоритеты и безопасность. - 2015. - №2. - С.41.

4. Казимагомедов А.А. Банковское дело: Организация и регулирование / А.А. Казимагомедов. - М.: Academia, 2018. - $320 \mathrm{c}$.

5. Картаев Ф.С. Полезно ли инфляционное таргетирование для экономического роста? [Полезно ли таргетирование инфляции для экономического роста?]. / Ф.С. Картаев. // Вопросы экономики. 2017. - №2. - С. 62.

6. Отчёт МВФ Развитые экономики // Международный Валютный Фонд [Электронный ресурс]. Режим доступа: http://www.imf.org/external/pubs/ft/weo/2015/01/pdf/statapp.pdf. - дата обращения: 7.02.2021.

7. Юдаева К.О возможностях, целях и механизмах денежно-кредитной политики в текущей ситуации / К.О. Юдаева. // Финансы. Вопросы экономики. - 2014. - №2. - С. 4.

8. Carriere-Swallow Y., Jacome L., Magud N., Werner, A. Central Banking in Latin America: The way forward. IMF Working Paper. - 2016. - September, pp. 1-42.

9. Castillo C. Inflation targeting and exchange rate volatility smoothing: A two-target, two-instrument approach. Economic Modeling. - 2014. - no. 43. - pp. 330-345.

10. Cortes G.S., Paiva C.A.C. Deconstructing credibility: The breaking of monetary policy rules in Brazil. Journal of International Money and Finance. - 2017. - no. 74. - pp. 31-52.

11. Durusoy S., Beyhan Z. Recent problem of global capitalism: Rate of exchange wars. Procedia Economics and Finance. - 2015. - no. 23. - pp. 992-999. doi: 10.1016/S2212-5671(15)00497-9.

12. Kerns J., Patel N. Does the financial channel of exchange rates offset the trade channel? BIS Quarterly Review, 2016, December, pp. 95.

13. Mishra P., Montiel P., Sengupta R. Monetary transmission in developing countries: Evidence from India. IMF Working Paper. - 2016. - August. - pp. 1-67. 